\title{
Discrete Set Entity Name Data Type
}

National Cancer Institute

\section{Source}

National Cancer Institute. Discrete Set Entity Name Data Type. NCI Thesaurus. Code C95688.

A data type comprised of a collection of a discrete set of entity names. 